\title{
Ultrasound-guided central venous access
}

\section{Paul Barash}

Address: Department of Anesthesiology, Yale University School of Medicine, Cedar St, New Haven, Connecticut 06520-8051, USA

Email: paul.barash@yale.edu

Fl000 Medicine Reports 2009, I:65 (doi:10.3410/MI-65)

The electronic version of this article is the complete one and can be found at: http://FI000.com/Reports/Medicine/content/I/65

\begin{abstract}
Central venous catheterization is a critical component of management for the critically ill patient in the operating room and intensive care unit. When using ultrasound techniques for central venous access, access is achieved with fewer attempts, a reduced incidence of carotid artery punctures or 'hits', an increased success rate, and a decreased duration of procedure compared to the traditional landmark approach.
\end{abstract}

\section{Introduction and context}

Central venous catheterization is a critical component of management for the critically ill patient in the operating room and intensive care unit [1]. Traditionally, the right internal jugular vein (RIJV) has been chosen as the firstchoice site of access. By use of certain landmarks (carotid artery, sterno-cleidomastoid muscle, and so on) vascular access is achieved. However, significant complications are associated with the technique [2]. This review will use catheterization of the RIJV as the model for ultrasound (US) guidance. With widespread use of US techniques, it is reported that successful RIJV catheterization is achieved with fewer attempts, a reduced incidence of carotid artery (CA) punctures or 'hits', an increased success rate and a decreased duration of procedure [3-6]. Before continuing it is important to emphasize that knowledge of both methods is required in clinical practice.

Percutaneous central venous catheterization achieved popularity due to three major historic events. First, the publication by Seldinger of a catheterization technique that progressively increased vascular catheter size by utilizing wire guides [7]. Second, with increased number of cardiac surgical procedures (coronary artery bypass graft), a need came about for rapid access to the central venous circulation for both monitoring hemodynamic function as well as delivering fluids and medications to the central circulation. Finally, the invention and development of the pulmonary artery catheter by Swan, Ganz, and colleagues gave clinicians extensive hemodynamic information at the 'bedside' [8]. Prior to the introduction of this catheter, the quantity and quality of hemodynamic information could only be achieved in a cardiac catheterization laboratory. The choice of RIJV access is based upon relative anatomic constancy, ease of access, large caliber, absence of venous valves, and direct route to the right atrium. In addition, the site is 'removed' from the surgical field. A key consideration for successful venous catheterization via the RIJV route is the anatomic relationship between the RIJV and the CA. As the patient's head is rotated from neutral $\left(0^{\circ}\right)$ to $90^{\circ}$, most authorities report a greater degree of overlap of the CA by the RIJV. This potentially can increase the number of CA hits [9-11]. Most experts therefore recommend the patient's head (facing left) to be in a lateral position of $30-45^{\circ}$ to puncture the RIJV. However, using different imaging modalities, others could not duplicate this anatomic relationship [12].

\section{Recent advances}

With the advent of clinical US techniques in the 1980s, it became evident that safer, more accurate, and more rapid access could be achieved [13]. Regulatory authorities have strongly recommended its use for central vascular access procedures. These guidelines in the United States and Great Britain fall just short of recommending mandatory use of US $[14,15]$. Royse [16] considers the 
clinical use of US as a spectrum from US-guided vascular catheterization and neural blockade to echocardiography. He suggests educational opportunities in this area should emphasize similar clinical challenges rather than differences in these approaches.

The critical research study in this area was published by Karakitsos et al. [3], who conducted a randomized prospective study comparing landmark-based techniques to US techniques for RIJV access. In an investigation with 450 patients in each group, they reported significant differences (US versus landmark) for access time (17 versus 44 seconds), success rate (100\% versus $94 \%)$, CA puncture (1\% versus $10 \%)$ and number of attempts (1 versus 3 ). The latter is important, since it is hypothesized that the number of attempts is related to complication rates and infection. Wigmore et al. [17] compared landmark-based and US techniques after the introduction of the National Health Service Vascular Access Guidelines. They also report (US versus landmark) a higher failure rate $(0.6 \%$ versus $6 \%)$, more attempts $(1.2$ versus 1.3$)$ and a higher complication rate $(2 \%$ versus $9 \%)$. One often-ignored benefit of US examination of the neck vessels is that it confirms the patency of the RIJV; it is indeed not uncommon to uncover an asymptomatic thrombosis in patients in whom a RIJV catheter has been used previously.

Education and training are key to the successful application of US-guided techniques; these involve knowing the basic principles of US, knowing classic and ultrasonographic anatomy, and training on phantoms to acquire the technical skills and eye-hand coordination. In clinical practice, US-guided RIJV access means visualizing the US anatomy, confirming RIJV presence and patency by compressing the vessel, and finally, confirming appropriate placement of needle and/ or wire guide [18]. However, one of the limits and causes of failure or complications with using US is that, at present, it is difficult to visualize the tip of the venipuncture needle. This is due, in part, to the needle design and the physics of the US system. $[19,20]$.

\section{Implications for clinical practice}

The most feared complication of RIJV access is placing an introducer or catheter into the CA. In the American Society of Anesthesiologists' Closed Claims Study, CA puncture was associated with the second largest 'payout'; cardiac tamponade was first [21]. There are two schools of thought in managing this problem. The first is 'watchful waiting' to determine if signs of vascular injury are observed, for example, increasing size of a hematoma, compromise of the airway by a hematoma, and neurological and/or vascular compromise. The second is immediate surgical or interventional radiological treatment of the vascular injury. The current literature suggests earlier surgical or interventional radiological treatment is preferable, depending on the nature of the injury and other co-morbidities [22-24].

Although this review focuses on RIJV catheterization, US is used for arterial cannulation as well as catherization of other venous sites. This includes peripheral venous access in patients with diminished anatomic signs of peripheral venous structures, percutaneous insertion of peripherally-inserted central catheters, and catheterization of the femoral vein. Even subclavian vein catheterization can now be achieved under US guidance by experts (supra- or subclavicular approach).

In closing, it is important to re-emphasize that one technique (landmark versus US) is not superior for all patients; knowledge of both methods is required in clinical practice. As more studies are published in this area, the advantage of US will be more easily discerned, and US-guided vascular access will be employed with greater frequency.

\section{Abbreviations}

$\mathrm{CA}$, carotid artery; RIJV, right internal jugular vein; US, ultrasound.

\section{Competing interests}

The author declares that he has no competing interests.

\section{References}

I. Graham AS, Ozment C, Tegtmeyer K, Lai S, Braner DA: Videos in clinical medicine. Central venous catheterization. $N$ Engl J Med 2007, 356:e21

2. McGee DC, Gould MK: Preventing complications of central venous catherization. N Engl J Med 2003, 348: I I23-33.

3. Karakitsos D, Labropoulos N, De Groot E, Patrianakos AP, Kouraklis G, Poularas J, Samonis G, Tsoutsos DA, Konstadoulakis MM, Karabinis A: Real-time ultrasound guided catheterization of the internal jugular vein: a prospective comparison with the landmark technique in critical care patients. Crit Care 2006, I0:RI62.

4. Sabbaj A, Hedges JR: Ultrasonographic guidance for internal jugular vein cannulation: An educational imperative, a desirable practice alternative. Ann Emer Med 2006, 48:548-50.

5. Espinet A, Dunning J: Does ultrasound guided central line insertion reduce complications and time to placement in elective patients undergoing cardiac surgery. Interact CardioVasc Thorac Surg 2004, 3:523-27.

6. Slama M, Novara A, Safavian A, Ossart M, Safar M, Fagon JY: Improvement of internal jugular vein cannulation using ultrasound guided technique. Intens Care Med 1997, 23:916-9.

7. Seldinger SI: Catheter replacement of the needle in percutaneous arteriography: a new technique. Acta Radiologica 1953, 39:368-76.

8. Swan HJ, Ganz W, Forrester J, Marcus H, Diamond G, Chonette D: Catheterization of the heart in man with use of a flowdirected balloon-tipped catheter. N EngIJ Med I970, 283:447-5 I. 
9. Troianos CA, Kuwik RJ, Pasqual JR, Lim AJ, Odasso DP: Internal jugular vein and carotid artery anatomic relation as determined by ultrasonography. Anesthesiology 1996, 85:43-8.

10. Lieberman JA, Williams KA, Rosenberg AL: Optimal head rotation for internal jugular vein cannulation when relying on external landmarks. Anesth Analg 2004, 99:982-8.

II. Sulek CA, Gravenstein N, Blackshear RH, Weiss L: Head rotation during internal jugular vein cannulation and the risk of carotid artery puncture. Anesth Analg 1996, 82:125-8.

12. Lim CL, Keshava SN, Lea M: Anatomical variations of the internal jugular veins and their relationship to the carotid arteries: A CT evaluation. Australasian Radiol 2006, 50:314-8.

13. Metz S, Horrow JC, Balcar I: A controlled comparison of techniques for locating the internal jugular vein using ultrasonography. Anesth Analg 1984, 63:673-9.

14. National Institute for Clinical Excellence: Guidance on the use of ultrasound locating devices for placing central venous catheters. Technology Appraisal Guidance No. 49 London: National Institute for Clinical Excellence; September 2002. [http://www.nice. org.uk/nicemedia/pdf/Ultrasound_49_guidance.pdf].

15. Rothschild JM: Ultrasound guidance of central vein catheterization. In Making Healthcare Safer: a Critical Analysis of Patient Safety Practices: Evidence Report/Technology Assessment no. 43. Edited by Shojania KG, Duncan BW, McDonald KM, Wachter RM: Rockville, MD: Agency for Healthcare Research and Quality; 200I:245-54.

16. Royse C: Ultrasound education in anaesthesia: Turning the tables on convention. Ann Cardiac Anaesth 2008, I I:77-9.
17. Wigmore TJ, Smythe JF, Hacking MB, Raobaikady R, MacCallum NS: Effect of the implementation of NICE guidelines for ultrasound guidance on the complication rates associated with central venous catheter placement in patients presenting for routine surgery in a tertiary referral centre. Brit J Anaesth 2007, 99:662-5.

18. Feller-Kopman D: Ultrasound guided internal jugular access: A proposed standardized approach and implications for training and practice. Chest 2007, 132:302-9.

19. French JL, Raine-Fenning NJ, Hardman JG, Bedforth NM: Pitfalls of ultrasound guided vascular access: the use of three/fourdimensional ultrasound. Anaesthesia 2008, 63:806-I3.

20. Chapman GA, Johnson D, Bodenham AR: Visualisation of needle position using ultrasonography. Anaesthesia 2006, 6I:|48-58.

21. Domino KB, Bowdle TA, Posner KL, Spitellie PH, Lee LA, Cheney FW: Injuries and liability related to central vascular catheters. Anesthesiology 2004, 100:141| I-8.

22. Peterfreund RA, Wargo JA: Errant central line placement. J Clin Anesth 2007, 19:479-81.

23. Eckhardt WF, laconetti J, Kwon JS, Brown E, Troianos CA: Inadvertent carotid artery cannulation during pulmonary artery catheter insertion. J Cardiothorac Vasc Anesth 1996, I0: 283-90.

24. Guilbert MC, Elkouri S, Bracco D, Corriveau MM, Beaudoin N, Dubois MJ, Bruneau L, Blair JF: Arterial trauma during central venous catheter insertion: Case series, review and proposed algorithm. J Vasc Surg 2008, 48:918-25. 